\title{
Erratum zu: LIFE+ Traisen: Der neue Fluss - die Umsetzung
}

\author{
Jürgen Eberstaller · Roland Schmalfuß - Doris Eberstaller-Fleischanderl • Hannes Gabriel · Thomas Kaufmann • \\ Helmut Wimmer · Mathias Jungwirth
}

Online publiziert: 6 . Oktober 2020

(C) Der/die Autor(en) 2020

\section{Erratum zu: \\ Österr Wasser- und Abfallw 2018 \\ https://doi.org/10.1007/s00506-018- 0474-8}

Der Artikel LIFE+ Traisen: Der neue Fluss - die Umsetzung von Jürgen Eberstaller, Roland Schmalfuß, Doris Eberstaller-Fleischanderl, Hannes Gabriel, Thomas Kaufmann, Helmut Wimmer und Mathias Jungwirth wurde ursprünglich am 13. März 2018 ohne „Open Access“ online auf der Internetplattform des Verlags publiziert. Die Autoren haben sich jedoch nachträglich für eine „Open Access“-Veröffentlichung entschieden. Das Urheberrecht des Artikels wurde deshalb 22 Juni 2020 in (c) Der/die Autor(en) 2018 geändert.

Die Online-Version des Originalartikels ist unter https: / /doi. org/10.1007/s00506-018-0474-8 zu finden.

DI Dr. J. Eberstaller $(\varangle)$.

DI D. Eberstaller-Fleischanderl ezb TB Eberstaller $\mathrm{GmbH}$, Austraße 78, 3512 Mautern, Österreich mautern@ezb-fluss.at

DI Dr. R. Schmalfuß · DI H. Wimmer VERBUND Hydro Power GmbH, Europaplatz 2, 1150 Wien, Österreich

DI H. Gabriel

DonauConsult Ingenieurbüro GmbH, Klopstockgasse 34, 1180 Wien,

Österreich

DI Dr. T. Kaufmann

freiwasser - Arbeitsgemeinschaft für Ökologie, Kulturtechnik und Wasserwirtschaft, Währinger Straße 135/18, 1180 Wien, Österreich

em. o.Univ.-Prof Dr. M. Jungwirth Institut für Hydrobiologie

und Gewässermanagement,

Universität für Bodenkultur Wien,

Gregor-Mendel-Straße 33, 1180 Wien, Österreich
Open Access. Dieser Artikel wird unter der Creative Commons Namensnennung 4.0 International Lizenz veröffentlicht, welche die Nutzung, Vervielfältigung, Bearbeitung, Verbreitung und Wiedergabe in jeglichem Medium und Format erlaubt, sofern Sie den/die ursprünglichen Autor(en) und die Quelle ordnungsgemäß nennen, einen Link zur Creative Commons Lizenz beifügen und angeben, ob Änderungen vorgenommen wurden.

Die in diesem Artikel enthaltenen Bilder und sonstiges Drittmaterial unterliegen ebenfalls der genannten Creative Commons Lizenz, sofern sich aus der Abbildungslegende nichts anderes ergibt. Sofern das betreffende Material nicht unter der genannten Creative Commons Lizenz steht und die betreffende Handlung nicht nach gesetzlichen Vorschriften erlaubt ist, ist für die oben aufgeführten Weiterverwendungen des Materials die Einwilligung des jeweiligen Rechteinhabers einzuholen.

Weitere Details zur Lizenz entnehmen Sie bitte der Lizenzinformation auf http://creativecommons.org/licenses/ by/4.0/deed.de. 